\title{
Research on the Security Policies for Cloud Computing
}

\author{
K.Sai Manoj
}

\begin{abstract}
The sizable progressive patterns in customary exchange and the need for non-public statistics to skip global outskirts featured the need to diagram protection pointers and inspire particular guidelines to improve the nicely-being of residents' close to home statistics. An modern jump beforehand, which makes stressful situations to the well being of individual records, is Cloud Computing. the rule of thumb highlight of Cloud Computing is that it allows on-name for arrange get admission to figuring property with least control assignment or company association collaboration. This new innovation gives new measurements to traditional exchanges of private records and due to this it has become easy to installed order a safety affiliation for Cloud Computing administrations. For the easy out of the plastic new age of Cloud Computing, the idea device of a fitness inclusion is to shield humans and data, set proposals for foreseen conduct with the valuable asset of customers, problem threats and help to tune consistence with guideline

This investigations paper centered at the development of a Cloud safety inclusion, in admire to facts insurance. basically focused on the model of programming as-an management (SaaS), this paper is meant to focus on a Framework for gatherings, clients, Cloud bearers and supply a gauge to the security inclusion of Cloud Computing. Pointed honestly on the protection requirements which is probably specific to Cloud circumstance, feature how those conditions connect to our Cloud well-being inclusion and endorse, the measures and the relating health regulations. except, it proposes a manner that might be observed with the manual of Cloud corporations for comparing the well being in their structures as, insurance is one of the internal abilties of the Cloud provide
\end{abstract}

\section{INTRODUCTION}

as of late, in interconnected worldwide each business enterprise dreams a pleasantly concept out protection inclusion. The short development of the realities age has quite changed the idea of Computing and gives ascend to an advanced association of insurance issues and issues. in step with the kingdom enormous Institute of measures and age (NIST), safety protection is portrayed as "general of mandates, preparations, recommendations, and practices that recommends how an agency oversees, ensures, and appropriates statistics" [1]. For the mechanical success of Cloud Computing, the concept device of a protection approach is to shield humans and actualities, set techniques for predicted behavior through clients, lower risks and track compliances with insights [2]. thinking about fact that nowadays real truly all and sundry with an enthusiasm for certainties duration has experience the term Cloud Computing [3] it's far basically pivotal to essentially shield as a number one mission the protection troubles in Cloud Computing: Are there any protection dangers in Cloud Computing, that do not appear in non-Cloud frameworks? Is

Revised Manuscript Received on September 14, 2019.

Dr.K.Sai Manoj, CEO Innogeecks Technologies and Amrita Sai Institute of Science and Technology, Vijayawada, AP, India.

(E-mail: ceo@innogeecks.com) the Cloud free and secure for the customers? As Cloud Computing is attaining acknowledgment, we mission to demystify the insurance and protection dangers which might be conveyed, due to its transformational nature [4]. The accomplishment of a Cloud guarantee inclusion easily depends upon on the way in which the safety substance are tended to. Like maximum age, Cloud Computing superior from a need. The placing increment of the internet has given rise to a modern polish of "net-scale" inconveniencesterrible conditions which joins the an increasing range of amount of facts on hand in net or the producing of giant spot carport in servers and the usage of additional cloud based absolutely applications stockpiling over protracted separations. As a need inside the first vicinity, essayist want to make reference to the proper that means of this age. The first-class impressively applied which means that of the Cloud Computing version is brought through using NIST, as "disbursed computing is a model for permitting well-known, nearby, on request network get right of phase to a mutual pool of configurable figuring assets (e.G. structures, servers, stockpiling, bundles, and administrations) that may be rapid provisioned and discharged with least oversee undertaking or supplier interaction".

\section{METHODOLOGY}

This Cloud form includes five massive inclinations, three supplier styles, and four Deployment fashions. Its "five imperative attributes" are: an) to be had to return again to artwork for self-guarantor, b) full-size network get to, c) useful manual pooling, d) brief flexibility, e) Measured issuer [5]. Its 3 backer fashions which is probably referenced to: programming software-as-a-supplier (SaaS), Platform-as-a-supplier (PaaS), Infrastructure-as-a-provider (IaaS). it is some distance powerful to be expressed, that every assist shipping model has idea approximately truely certainly one of a kind executions, which confounds the improvement of present day-day fitness variation that is probably received thru others, as Cloud Computing clients or transporters or Cloud contributions. Its four Deployment patterns which is probably isolated into, three commonly applied models and a furthermore one which can be: The three often carried out Cloud Deployment molds: a) private Cloud: is an assembled and overseen internal a solitary business corporation undertaking, b) Public Cloud: is a tough and fast of Computing belongings equipped through 1/three-birthday party agencies, c) Hybrid Cloud: is a combination of figuring property gave thru each non-open and open mists. moreover, the greater tremendous rendition, it's far a ton drastically less-for the most element applied and it's miles the: community Cloud: shares registering 
belongings sooner or later of a few institutions, and can be overseen via approach for the usage of the use of every hierarchical IT resources or 0.33-birthday happy celebration corporations. [6][7][8][10][11][12] overseeing such heterogeneous patterns, to satisfy coverage wishes is a perplexing assignment, considering clashes more than one the health stipulations and amongst safety controls at every layer of Cloud. From the Cloud organizations' contemplations set, nicely-being calls for a whole part of charges (guarantee preparations' licenses) and outcomes and is a tough hassle to perform. So Cloud institutions want to seize customers' problems and are searching out new protection arrangements that settle such issues. As Cloud Computing is doing prominence, its multidisciplinary has delivered up troubles in the examinations community kind of how novel 20 this new worldview is on account that it contains of without a doubt the complete element that gift innovation as of now do [13]. The technique, furnished in this Thesis, uses the Threats associated with the product asan agency form and diagnosed with the Cloud guarantor. We pick out out this one to inquire approximately in our exploration, as it remains the triumphing Cloud model for the motive that it rearranges arrangement and diminishes patron procurement prices. almost about its qualities, it's far furthermore available from any spots, its updates are being automatic, it is pleasantly ok during multiple devices and its devices is probably with out trouble modified in accordance with specific customer's needs. The SaaS version has prospered within the gift years in moderate of the numerous focal elements it gives, so we selected to verify this one. The critical element intention of the proposed method offers a yearning to the wellness nerve-racking states of a SaaS Cloud Computing shape. at the off danger that the Cloud organizations test out the proposed model, they may accumulate having a draw close warranty Audit and because of this an over the pinnacle segment of insurance of their Cloud Computing condition, setting aside coins and time.

safety inconveniences for Clouds there are various insurance problems for distributed computing since it consists of severa extra noteworthy duration which encompass of which joins structures and network collusion time, databases, strolling systems, automatic reality, virtualization, excessive best useful asset planning, trade manipulate contraption, load adjusting, measurements site traffic controls, simultaneousness control, aggregate manipulate and reminiscence control. accordingly, assurance inconveniences for bunches of these related structures and advancements are pertinent to allotted computing environment. as an instance, the associated community that interconnects the inner systems in a cloud should be cozy inner blessing condition. Virtualization worldview in allotted computing results in hundreds of insurance issues. for example, mapping the advanced machines to the large machines want to be finished efficiently. facts protection accommodates of scrambling the realities further to ensuring that appropriate clues are legal for measurements sharing. in addition, beneficial asset distribution and reminiscence control calculations ought to be comfortable. in this manner, records mining techniques might be cloth to malware discovery in mists [9].
Exacting assessment indicating assurance in Cloud Computing:distributed computing is known as one of the widespread subsequent topics in statistics time global [17]. due to its constructing layout and propensities (Flexibility/Elasticity, Scalability of foundation, massive community get admission to, Reliability, Sustainability) forces some of protection favors which include of centralization of nicely being, repetition, insights division and useless accessibility [18][19]. however truth that there are numerous benefits from embracing Cloud Computing, there furthermore are more than one great regulations related to/with reference to its choice. The excellent in magnificence issues conveyed via manner of manner of using the Clouds, which comprise calculation reappropriating, valuable fine manual sharing and out of doors actualities warehousing, development the protection and privacy troubles and make new assurance horrifying situations. similarly to that, the large length of the Clouds, the direct access Cloud basis and the multiplication of cellular get right of segment to gadgets grow Cloud vulnerabilities and dangers. therefore, as Clouds' acknowledgment develops relentlessly, an increasing extensive variety of guarantee issues are raised, giving them a chance to turn out to be more attractive as attack focuses because of the eye of superior belongings. In sizable, insurance is identified with the vital additives of class, honesty and accessibility.

\section{III.DISCUSSIONS \& RESULTS}

In Cloud Computing, the ones simple components of nicely being, comply with the 3 instructions of possessions which may be vital to be confirmed: certainties, programming software software and gadget assets. earlier than we continue with the advent of the Cloud coverage stressing activities proposed through the Cloud basis, we need to to start with make smooth what Cloud Computing protection approach correspondingly to find out and understand what the guarantee issues are. We also need to find out the Cloud coverage ascribes and to discover the safety necessities which joins secrecy, uprightness, accessibility notwithstanding straightforwardness. security in Cloud Computing alludes to the association of methodologies, strategies and requirements intended to provide measurements well being make sure in a Cloud Computing condition. It has a tendency to every tremendous and clever safety troubles inside the route of all the particular provider models of programming task, Platform and Infrastructure and it handles moreover how the ones administrations are conveyed (Public, non-open or Hybrid delivery shape) [20]. 28 security inconveniences are isolated into instructions, in accordance with one in the entirety approximately kind partners: inconveniences went up towards via Cloud businesses (bunches giving SaaS, PaaS or IaaS via the cloud) and issues stood as a good deal as with the aid of manner in their clients (places of work or companies who have programs or maintain records at the Cloud). each one has its personal requirements and aptitudes familiar from one companion with the inverse. In every one of the 3 paperwork, the Cloud business company oversees 
and controls the foundations. The partnership is answerable for forcing and going for strolls affordable framework controls of massive essentialness, collectively with guidance, firewalls, physical protection and others. however, in each one of the 3 forms, the clients have rights and responsibilities at the same time as in transit to permit them to make greater outstanding gifted selections in advance than joining with a commercial enterprise project. Gartner manages underneath those seven rights and responsibilities that benefit each dealer dealers and management customers [21]. 1. The privilege to preserve possession, Use and control of 1 's close to domestic facts.

2. The first-rate viable to assist diploma Agreements that adapt to Liabilities, Remediation and enterprise affiliation results.

3. The privilege to Notification and inclination about changes that impact the administration consumer's organisation supervisor systems.

four. The excellent possible to understand the Technical constraints or conditions of the administration in advance of time. 5. The privilege to cozy the criminal necessities of Jurisdictions in which the economic business enterprise challenge works 6 . The tremendous possible to understand what insurance office work the provider pursues.

7. The willpower to apprehend and to stick to programming program License necessities.

\section{CONCLUSION}

disbursed computing is a very encouraging innovation that offers institutions lessen strolling costs on the indistinguishable time as increasing in preferred execution. certainly, even dismissing the truth that Cloud Computing has been conveyed and used underway conditions, protection in Cloud Computing keeps on being in its early ranges and goals additional exam diversion. experts have analyzed numerous essential problems for trusted Cloud Computing frameworks, and severa modern-day works speak desired issues on Cloud properly-being and privacy. To preserve commercial corporation assignment congruity, the SaaS partnership need to have an arrangement of nicely being highlights. in this idea, we've proposed a security form that gives a course to the properly-being tense states of a Cloud guarantor in a SaaS Cloud Computing condition. within the occasion that the Cloud agencies take a gander at the proposed variation, the utilization of the doors sports of our safety safety, they'll accomplish accomplishment to have a draw close fitness Audit version of Cloud Computing and because of this an over the top popularity of guarantee of their Cloud Computing scenario. in this way, the most excessive considerable conviction from this check out is, the making of a confided in Cloud backer guarantor that accomplishes the desired assure prepare and bounds the peril of the man or woman's statistics. In light of the facts gave in this look at, through the examination of case look at and the given occurrence of e-well-being protection within the Europe, much like a fear for the eu rate (EC), we characterized the base requirements for the wellbeing of eproperly being frameworks, sorted the inclusion guidelines and envelop them in clean virtual assurance guidelines. mixed in with the general recommendations which may be provided on this postulation, the ones proposals need to shape the notion for the development of an in style safety confirmation for the crucial Infrastructures and will see pertinent property, in Cloud Computing systems. similarly, our proposals that take a look at with specific use times and specialized foundations and belongings by means of manner of and large despatched, in expressions of their assure measures, can also moreover need to apply as an inexpensive guide for businesses and Cloud transporters.

\section{REFERENCES}

1. Country wide Institute of standards and technology, structures, "manual for developing protection plans for federal facts structures", vol. 800-18, February 2006, [Online]. To be had from: http://csrc.Nist.Gov/guides/nistpubs/800-18-Rev1/sp80018-Rev1-very last.Pdf/, [accessed December 2013]. [2] Divers S. - SANS Institute, "information safety coverage A development manual for huge and small businesses", November 2007, pp. Forty three-forty four.

2. Svantesson D. And Clarke R., "privateness and client dangers in Cloud Computing", computer regulation and protection assessment, vol. 26, 2010, pp. 391-397

3. Kshetri, N., "privacy and protection issues in Cloud Computing: the area of establishments and institutional evolution". 2012, Bryan college of business agency and Economics, The Univ. Of North Carolina at Greensboro, NC27402-6165,the us

4. national Institute of standards and era."The NIST Definition of Cloud Computing" (PDF), September 2011. [Online]. To be had from: https://csrc.Nist.Gov/publications/element/sp/800-a hundred forty five/very last, [accessed November 2013].

5. ecu network and facts safety organisation (Enisa), "Cloud Computing blessings, dangers and tips for information protection", November 2009, [accessed June 2012]. [7] Arnold S., "Cloud Computing and the issues of privateness", July 2009, KM global, pp.14-22

6. Whitepaper, A, "organization Cloud Computing: transforming IT", Platform Computing, considered 13 March 2010, pp.6.

7. Xia Z., Zhu Y., solar X. And Chen L. (2014), "comfy semantic increase based clearly are trying to find over encrypted cloud records helping similarity score "magazine of Cloud Computing", Springer three.1, pp. 111. [10] Kuyoro S.O., "Cloud Computing safety troubles and disturbing conditions", Proc. Worldwide mag of pc Networks (IJCN), 2011, vol. 3, problem: 5.

8. KavithaV. And Subashini S.,"A survey on protection troubles in company transport fashions of cloud", globa journal of community and computer applications, January 2011, vol. 34 difficulty 1, pp.1-11 [12] Robinson N., Valeri L., Cave J., Starkey T., Graux H., Creese S., Hopkins P.: The Cloud: knowledge the safety, privacy and receive as true with challenges. Organized for the Unit F.Five, Directorate- popular information Society and Media, ecu fee (2010)

9. Pallis, George. "Cloud Computing: the cutting-edge Frontier of internet Computing." IEEE net Computing 14.Five (2010): 70-seventy three. [Online]. To be had from:

http://cgi.Di.Uoa.Gr/ advert/M155/Papers/palisic10.Pdf, [accessed November 2012].

10. Securing the Cloud: A assessment of Cloud Computing, security Implications and first rate Practices". To be had from :http://www.Centurylinktechnology.Com/internet 
Websites/default/documents/savvis_vmw_whitepaper_08 09.Pdf [accessed January 2013]. [15] Sans Institute, "An advent to Securing a Cloud surroundings", June 2012. [Online]. Available

from: https://www.Sans.Org/analyzingroom/whitepapers/cloud/advent-securing-cloudenvironment34052 [accessed November 2012].

11. Cloud protection Alliance: "The notorious 9: Cloud Computing top Threats in 2013". [Online]. To be had from: http://www.Cloudsecurityalliance.Org/topthreats/, 2013139

12. D. Lekkas, setting up and handling keep in mind within the public key infrastructure, laptop Communications 26 (16) (2003). [18] G. Reese, Cloud application Architectures: building applications and Infrastructure in the Cloud, in: idea in exercising, O'Reilly Media, 2009.

13. B. Rajkumar, C. Yeo, S. Venugopal, S. Malpani, Cloud computing and developing IT systems: vision, hype, and fact for turning in computing due to the fact the 5th software program, destiny era laptop systems (2009)

14. chance factors And safety troubles In various Cloud storage Operations Dr.Good enough.Sai Manoj quantityeight hassle-12, October 2019, ISSN: 2278-3075 (online) posted with the aid of: Blue Eyes Intelligence Engineering \& Sciences e book (First author) (ELSEVIER Scopus)

15. Conceptual orientated research on the development of the Cloud records storage safety Dr.Ok.Sai Manoj international magazine of laptop technology developments and era (IJCST) - extent 7 problem 5, Sep - Oct 2019.

16. Cloud protection: hazard elements and safety problems in cutting-edge-day inclinations Dr.Good enough.SaiManoj international magazine of Engineering \& technology, technological know-how Publishing business enterprise October 2019 (Scopus)

\section{ACKNOWLEDGEMENTS}

This paper heartily dedicated to beloved Honble Secretary and Correspondent Sri. K.Ram Mohan Garu,

\&Smt.K.Bhavani Devi Garu Amrita Sai Institute of science and technology. Also to all the respected Amrita Sai Management members. My special thanks to the Innogeecks technologies, Vijayawada for their technical support in all the aspects

\section{AUTHORS' INFORMATION}

Dr K Sai Manoj, Founder and Executive Director of Innogeecks Global Services Pvt Ltd, Founder and CEO of Innogeecks Technologies and Founder of 3 start-ups based on IOT and Cloud Computing, is an Enthusiastic learner, Excellent
Financial Advisor, Innovative and Visionary Leader, Insightful team builder and strategic planner, who has 10+ years of experience in Financial Services, Equity Research and IT- ITeS services to his credit. He has worked in Reputed Companies like WIPRO Technologies, Fidelity Inverstments.etc.,

He is Proud of achieving many laurels in the field of Computers and Research. He is a Certified Ethical hacker, Certified Computer hacking forensics Investigator, Certified Security Analyst, Charted Engineer from IEI (India), Certified Blockchain Expert, Microsoft Certified Technology Specialist, AWS Certified Solutions Architect-Associate, Google Analytics Individual Qualification, IBM Block chain Certification, Certified EC Council Instructor and so on.

He has a proven record of having $10+$ certifications from the most sought after software giants such as Microsoft, IBM, Google, Face book, EC Council \& Amazon besides this he has acted as a reviewer for the Journal of Super Computing (Springer), Journal of Big Data (Springer) and Journal of the Institution of Engineers (India) - Series B (Springer). And also with his solid financial advice 21 start-ups of Kochi, Bangalore and Vijayawada have tread the success track.
Talking about his research excellence, it is exciting to know that he has filed 3 patents and 4 more are in pipeline and has Published more than 25 research papers in reputed journals like Thomas Reuters, IEEE, Scopus etc., and shows keenness in researching on Cyber Security, Cloud Computing, Big Data / Hadoop, Block chain and Data Analytics. 